\title{
The experimental investigation of the HPAM/phenolic resin deep profile system in fractured low-permeability reservoirs
}

\author{
Wei Zhou ${ }^{1,2}$, Daiyin Yin ${ }^{1,2}$, Yazhou Zhou ${ }^{1,2}$ \\ ${ }^{1}$ Key Laboratory of Enhanced Oil Recovery (Northeast Petroleum University), Ministry of Education, Daqing 163318, China \\ ${ }^{2}$ Department of Petroleum Engineering, Northeast Petroleum University, Daqing 163318, China
}

\begin{abstract}
The problem of injected water channeling along fractures exists in the process of water injection in fractured low permeability reservoir, aimed at this problem, deep profile control technology applies to plug fractures to improve the recovery of low permeability reservoir. In this paper, partially hydrolyzed polyacrylamide (HPAM) is used as water-plugging/profile-modifying agent and phenolic resin as crosslinker agent. Several profile control systems are tested to find the one which is suitable for fractured low permeability reservoirs. The performances of profile control systems are evaluated, and effects of formation water salinity, that of shearing rate and that of temperature on the performance are studied. Finally, in order to study effects of this profile control system on displacing oil, flowability experiment and core displacement experiment are applied. It shows that with the increase of salinty of prepared water and the increase of the shearing rate, the viscosity of this system decreases. With the increase of temperature, the gelling time shortens, the viscosity increases, but the stability weekens. This kind of profile control system has a good effect on plugging fractures of low permeability cores. After water flooding,this kind of profile control system is injected into cores, the recovery ratio can increase $3.5 \%$. So the profile control system composed of HPAM/ phenolic resin can apply to deep profile control in fractured low permeability reservoir to enhance oil recovery.
\end{abstract}

\section{Introduction}

Low-permeability reservoirs are widely distributed. Taking China as an example, most of the newly discovered reservoirs are low-permeability reservoirs. Currently, oil reserves in low-permeability oilfields account for approximately $40 \%$ of oil resources and have considerable exploitation potential [1-3]. Generally, lowpermeability oilfields have naturally developed fractures that form connected channels [4]. Injected water flows into oil wells along the connected channels, so it is difficult for injected water to enter into the lowpermeability matrix. Thus, it is difficult for oil in a lowpermeability matrix to be displaced effectively. This is the main reason why water flooding is not effective in most fractured low-permeability oilfields [5]. Once fractured low-permeability reservoirs enter the middle and high water cut stages, it is more difficult to further enhance oil recovery. Because of fracture connectivity, surfactant flooding and microemulsion flooding cannot be applied [6,7]. However, a profile control agent can be injected into reservoirs [8-10]; the gelling time of the profile control agent can be controlled, and the low viscosity of the profile control agent in the formation ensures injectability. When a profile control agent reaches the deep part of a reservoir, it can be gelled, and the viscosity increases significantly. Therefore, the gelled profile control agent can plug fractures, which can make the subsequently injected water enter the lowpermeability matrix and displace the remaining oil to further improve the recovery of the fractured lowpermeability reservoir[11,12]. To date, few profile control systems have been designed for fractured lowpermeability reservoirs. Therefore, in this paper, HPAM is used as a water-plugging/profile-modifying agent, and phenolic resin is used as a crosslink agent. The performance of the profile control system, plugging ability of the profile control system, and displacement effect are evaluated. This paper can guide the development of fractured and low-permeability reservoirs in the high water cut stage.

\section{Experiment}

\subsection{Experimental materials}

HPAM is used as the main agent, and the tested HPAM molecular weights are 6 million, 8 million, 10 million and 12 million. Phenolic resin was used as the crosslink agent, ammonium chloride was used as the stabilizer, and thiourea was used as the deoxidizer. The HPAM/phenolic resin solutions were prepared by injecting water, 10 million molecular weight HPAM (concentration: $200 \mathrm{mg} / \mathrm{L}$ ), phenolic resin (concentration:

Corresponding author's E-mail: zhouwei111@petrochina.com.cn 
$200 \mathrm{mg} / \mathrm{L}$ ), ammonium chloride (concentration: 300 $\mathrm{mg} / \mathrm{L}$ ) and thiourea (concentration: $200 \mathrm{mg} / \mathrm{L}$ ). The experimental cores are natural cores from fractured lowpermeability reservoirs in the Daqing Oilfield, which are then fractured by artificial methods. The experimental oil is a simulated oil comprised of kerosene and crude oil from a Daqing low-permeability reservoir, and the viscosity of the experimental oil (at approximately $45^{\circ} \mathrm{C}$ ) is approximately $8 \mathrm{mPa} \cdot \mathrm{s}$. The salinities of the simulated formation water and simulated injected water are 5888.4 $\mathrm{mg} / \mathrm{L}$ and $485 \mathrm{mg} / \mathrm{L}$, respectively.

\subsection{Experimental instrument}

The instruments used include an ES-120 electronic analytical balance, a high-speed agitator, a triaxial stress machine, a Brookfield DV-III Programmable rheometer, an NDJ-4 viscometer, an HW-4A double thermostat, and an ISCO pump.

\subsection{Experimental steps}

\subsubsection{Measurements of Gels' Viscosity. (1)} According to the designed profile control agent formula, the mass of each chemical agent was weighed by an ES120 electronic analytical balance. HPAM with simulated injected water is prepared as a solution, and then the solution is stirred by using a KJ-1 agitator. (2) When the solution became evenly mixed (after approximately 2 hours), it stops maturing. (3) After maturation, the solution is stirred using a KJ-1 agitator, and the measured phenolic resin, ammonium chloride and thiourea are added. (4) A constant temperature water bath is set to $45^{\circ} \mathrm{C}$, and the initial viscosity of the profile control agent is measured by a rotary viscometer. (5) The temperature of the prepared solution is controlled with a heater, which is set at $45^{\circ} \mathrm{C}$, and the viscosity is measured regularly.

2.3.2 Preparation of fractured cores. Because it is difficult to obtain naturally fractured cores through coring, fractures are made by artificial methods. (1) The natural core is put into the triaxial stress machine. (2) The cores are subjected to a triaxial load to induce fractures, and the fracture opening pressure and fracturing pressure are recorded. (3) The core is loaded to an axial pressure between the fracture opening pressure and fracturing pressure. The core is loaded for one week to induce fractures. (4) The axial stress is changed to induce different fractures.

\subsubsection{Determination of the resistance coefficient} and residual resistance coefficient. (1) To simulate the progress of shearing when the profile control agent flows across perforation tunnels, the prepared solution is sheared until the viscosity decreases to $50 \%$. (2) After being vacuumed, the core is injected by simulated formation water to determine the pore volume. (3) According to the pressure difference between the inlet and outlet ends, the core is injected with simulated injected water at a rate of $0.12 \mathrm{ml} / \mathrm{min}$ to determine the water-phase permeability. (4) The core is injected with the solution at approximately $0.05 \mathrm{PV}$ at the same injection speed until the pressure is stable at both the inlet and outlet ends, and the resistance coefficient of the core is calculated. (5) Then, the core is injected with simulated injected water at the same speed until the pressure is stable, and the residual resistance coefficient is calculated.

2.3.4 Core displacement experiment. (1) The fractured core is vacuumed for 4 hours and saturated with simulated formation water to measure porosity. (2) The oil is driven out by water until the core no longer produces water, and the initial oil saturation is calculated. (3) The core is injected with simulated injected water at a rate of $0.12 \mathrm{ml} / \mathrm{min}$ until the water content of the outlet increases to $98 \%$, and the water-drive recovery of the core is calculated. (4) The core is injected with solution at the same rate for $0.05 \mathrm{PV}$, and the increment of recovery is calculated. (5) The core is injected with simulated injected water until the water content of the outlet increases up to $98 \%$, and the final recovery ratio is determined.

\section{The Performance Evaluation of HPAM/Phenolic Resin Gel}

\subsection{The Effect of Salinity On Viscosity Of HPAM/Phenolic Resin Gel}

Solutions are prepared by using water at different salinities $(1000 \mathrm{mg} / \mathrm{L}, 2000 \mathrm{mg} / \mathrm{L}, 3000 \mathrm{mg} / \mathrm{L}, 4000$ $\mathrm{mg} / \mathrm{L}$ and $5000 \mathrm{mg} / \mathrm{L})$. The other agents are 10 million molecular weight HPAM (concentration: $1500 \mathrm{mg} / \mathrm{L}$ ), phenolic resin (concentration: $200 \mathrm{mg} / \mathrm{L}$ ), ammonium chloride (concentration: $300 \mathrm{mg} / \mathrm{L}$ ), and thiourea (concentration: $200 \mathrm{mg} / \mathrm{L}$ ). The changes in the viscosities of different solutions after gelling are measured, as shown in Figure 1.

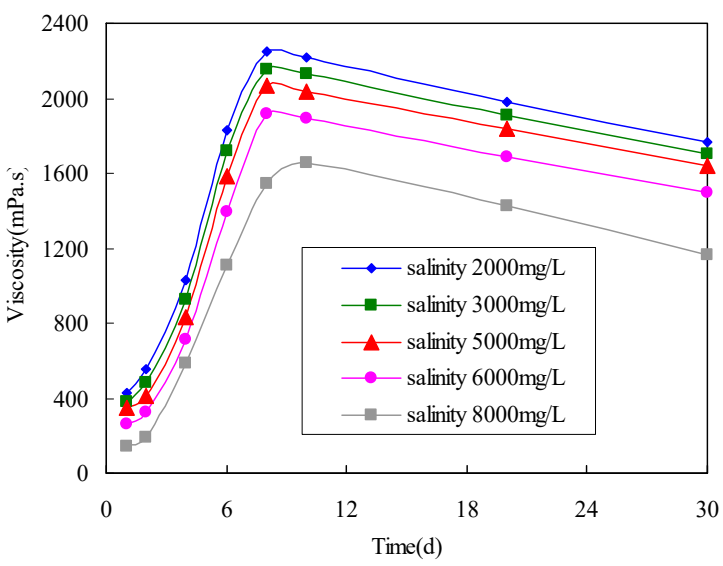

Figure 1 Changes in the viscosities of gels made with water with different salinities

As shown in the figure, with the increase in salinity, the viscosity of the solution after gelling decreases. The 
main reason for this finding is that when the salinity of the prepared water increases, the concentrations of $\mathrm{Ca}^{2+}$ and $\mathrm{Mg}^{2+}$ increase, and $\mathrm{Ca}^{2+}$ and $\mathrm{Mg}^{2+}$ react with the carboxyl group of the HPAM molecular chain to form a precipitate that has a negative effect on the viscosity of the gel. When the salinity of the prepared water is $1000 \sim 3000 \mathrm{mg} / \mathrm{L}$, the salinity has little effect on gel formation. When the salinity of the water is more than $5000 \mathrm{mg} / \mathrm{L}$, the salinity has a great influence on the gel formation of the HPAM/phenolic resin gel. When the salinity of the water is $5000 \mathrm{mg} / \mathrm{L}$, the viscosity of the gel can still reach $1919 \mathrm{mPa} \cdot \mathrm{s}$, but after 30 days, the viscosity decreases to $1498 \mathrm{mPa} \bullet \mathrm{s}$. Because the salinity of formation water in Daqing Oilfield's fractured lowpermeability reservoir is $5888.4 \mathrm{mg} / \mathrm{L}$, this kind of profile control agent can be applied in the Daqing Oilfield.

\subsection{Effect of Shearing Rate on HPAM/Phenolic Resin Gel Viscosity}

The viscosity of the solution, which follows the above solution formula, is measured after shearing at different rates, as shown in Figure 2.

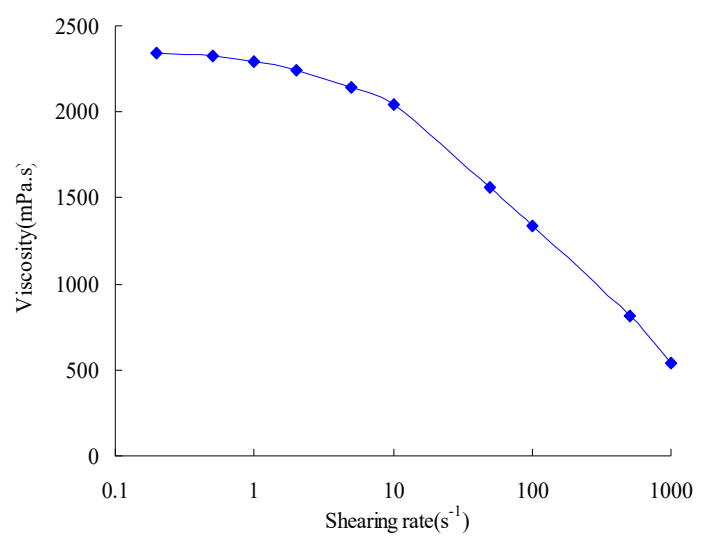

Figure 2 Effect of shearing rate on HPAM/phenolic resin gel viscosity

As shown in the figure, with the increase in the shearing rate, the viscosity of the solution after gelling decreases. When the shearing rate is less than $10 \mathrm{~s}^{-1}$, the viscosity decreases with increasing shearing rate. When the shearing rate is $10 \mathrm{~s}^{-1}$, the viscosity of the gel can reach $2045 \mathrm{mPa} \cdot \mathrm{s}$, and the viscosity retention rate is $87.41 \%$. When the shearing rate is more than $10 \mathrm{~s}^{-1}$, the viscosity of the gel decreases significantly with increasing shearing rate. When the shearing rate is 1000 $\mathrm{s}-1$, the viscosity of the gel is only $543 \mathrm{mPa} \cdot \mathrm{s}$, and the viscosity retention rate is $23.21 \%$.

\subsection{Effect of Temperature on HPAM/Phenolic Resin Gel Viscosity}

The viscosity of solutions that follow the above solution formula is measured at $30^{\circ} \mathrm{C}, 45^{\circ} \mathrm{C}$ and $60^{\circ} \mathrm{C}$. The results are shown in Figure 3.

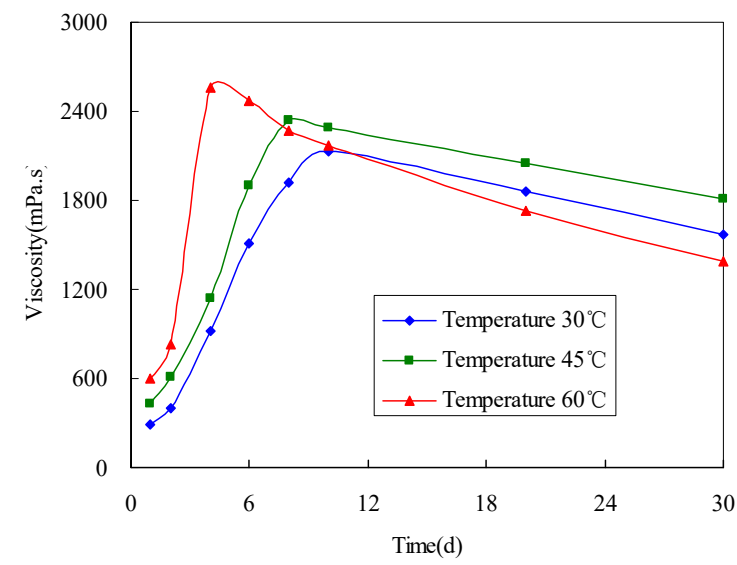

Figure 3 Effect of temperature on HPAM/phenolic resin gel viscosity

As shown in the figure, temperature has a large effect on the gelling time of HPAM/phenolic resin gels. With increasing temperature, the gelling time shortens, the viscosity increases, but the stability of the gel weakens. At $30^{\circ} \mathrm{C}$, the viscosity of the gel reaches a maximum viscosity of $2120 \mathrm{mPa} \cdot \mathrm{s}$ in 10 days, and after 30 days, the viscosity decreases to $1569 \mathrm{mPa} \bullet \mathrm{s}$. At $45^{\circ} \mathrm{C}$, the viscosity reaches the maximum viscosity of $2340 \mathrm{mPa} \cdot \mathrm{s}$ in 8 days, and after 30 days, the viscosity decreases to $1814 \mathrm{mPa} \cdot \mathrm{s}$. At $60^{\circ} \mathrm{C}$, the viscosity reaches the maximum viscosity of $2560 \mathrm{mPa} \cdot \mathrm{s}$ in 4 days, and after 30 days, the viscosity decreases to $1391 \mathrm{mPa} \cdot \mathrm{s}$. Thus, this kind of profile control agent can be applied in the Daqing Oilfield.

\section{Evaluation of the Profile Control of HPAM/Phenolic Resin Gel}

\subsection{Core fluidity experiment}

Cores fractured by artificial methods were injected by the solutions. The permeabilities of the cores were $10 \times 10^{-3} \mu \mathrm{m}^{2}, 20 \times 10^{-3} \mu^{2}, 30 \times 10^{-3} \mu \mathrm{m}^{2}$ and $50 \times 10^{-3} \mu \mathrm{m}^{2}$. The resistance coefficient and residual resistance coefficient were measured to study the effect of solutions after gelling on plugging the fractures, as shown in Table 1.

\begin{tabular}{c|c|c|c|c|c}
\multicolumn{7}{c}{ Table 1 Resistance coefficient and residual resistance coefficient of cores } \\
\hline $\begin{array}{c}\text { Core } \\
\text { label }\end{array}$ & $\begin{array}{c}\text { Permeability } \\
\left(\times 10^{-3} \mu \mathrm{m}^{2}\right)\end{array}$ & $\begin{array}{c}\text { Permeablity after } \\
\text { plugging }\left(\times 10^{-3} \mu \mathrm{m}^{2}\right)\end{array}$ & Plugging rate $(\%)$ & $\begin{array}{c}\text { Resistance } \\
\text { coefficient }\end{array}$ & $\begin{array}{c}\text { Residual } \\
\text { resistance } \\
\text { coefficient }\end{array}$ \\
\hline$\# 1$ & 15.78 & 0.12 & 99.26 & 129 & 96 \\
\hline$\# 2$ & 24.32 & 0.62 & 97.45 & 118 & 85 \\
\hline$\# 3$ & 37.89 & 1.23 & 96.75 & 97 & 70 \\
\hline$\# 4$ & 51.42 & 2.28 & 95.56 & 78 & 61 \\
\hline
\end{tabular}


As shown in the table, HPAM/phenolic resin gel has a good plugging effect on fractured cores. For all the core permeabilities tested, the plugging rates all exceed $95 \%$, the resistance coefficients all exceed 78 , and the residual resistance coefficients all exceed 61 .
After water flooding, cores were injected solely to study the displacement effect of the solutions. After water flooding, cores are injected soltions to study the displacement effect of the solutions, the core displacement test results is shown in Table 2.

\subsection{Core displacement experiment}

Table 2 Core displacement test results

\begin{tabular}{|c|c|c|c|c|c|c|}
\hline Core lable & $\begin{array}{l}\text { Permeability } \\
\left(\times 10^{-3} \mu \mathrm{m}^{2}\right)\end{array}$ & $\begin{array}{l}\text { Porosity } \\
(\%)\end{array}$ & $\begin{array}{l}\text { Initial oil } \\
\text { saturation } \\
(\%)\end{array}$ & $\begin{array}{c}\text { Water flooding } \\
\text { recovery } \\
(\%)\end{array}$ & $\begin{array}{l}\text { Enhanced oil } \\
\text { recovery by } \\
\text { gel flooding } \\
\qquad(\%)\end{array}$ & $\begin{array}{c}\text { Final recovery } \\
(\%)\end{array}$ \\
\hline$\# 1$ & 16.97 & 17.23 & 58.62 & 28.24 & 3.32 & 31.56 \\
\hline$\# 2$ & 27.56 & 18.02 & 59.16 & 30.64 & 3.45 & 34.09 \\
\hline$\# 3$ & 34.63 & 18.31 & 60.28 & 32.18 & 3.73 & 35.91 \\
\hline$\# 4$ & 47.28 & 18.57 & 59.95 & 34.79 & 3.95 & 38.74 \\
\hline
\end{tabular}

As shown in the table, the profile control agent has a good profile control effect and driving effect. For lowpermeability cores with permeabilities of $16.97 \times 10^{-}$ ${ }^{3} \sim 47.28 \times 10^{-3} \mu \mathrm{m}^{2}$, the gel solution was injected after water flooding, which improved oil recovery by $3.32 \% \sim 3.95 \%$ on the basis of water flooding. This indicates that HPAM/phenolic resin gel can be used in in-depth profile control of fractured low-permeability reservoirs. This type of gel can block fractures and water flow channels and displace residual oil to further improve the recovery of fractured low-permeability reservoirs.

\section{Conclusion}

(1) For HPAM/phenolic resin gel, with the increase in the salinity of the prepared water and the increase in the shearing rate, the viscosity of the gel decreases. With increasing temperature, the gelling time shortens and the viscosity increases, but the stability weakens.

(2) HPAM/phenolic resin gel exhibits a good plugging effect in fractured low-permeability cores. After water flooding, cores were injected by this kind of solution, and the recovery is increased by $3.32 \%-3.95 \%$ on the basis of water flooding.

(3)This indicates that HPAM/phenolic resin gel can be used in in-depth profile control of fractured lowpermeability reservoirs. This type of gel can block fractures and water flow channels and displace residual oil to further improve the recovery of fractured lowpermeability reservoirs.

\section{References}

1. Hu W R, Wei Y, Bao J W. Development of the theory and technology for low permeability reservoirs in China. Pet Explor Dev 2018; 45(4): 685-697.

2. Jia C Z, Zou C N, Yang Z, Zhu R K, Chen Z X, Zhang B, et al. Significant progress of continental petroleum geology theory in basins of Central and Western China. Pet Explor Dev 2018; 45(4): 546560.

3. Wang D Q, Yin D Y, Zhou Y Z. Fine classification of ultra-low permeability reservoirs around the Placanticline of Daqing oilfield (PR of China). J Petrol Sci Eng 2019; 174: 1042-1052.

4. Zhang C L, Wang P, Song G L, Qu G D, Liu J L. Optimization and evaluation of binary composite foam system with low interfacial tension in low permeability fractured reservoir with high salinity. J Petrol Sci Eng 2018; 160: 247-257.

5. Standnes D C. Experimental study of the impact of boundary conditions on oil recovery by co-current and counter-current spontaneous imbibition. Energy Fuels 2004; 18(1): 271-282.

6. Kamranfar P, Jamialahmadi M. Effect of surfactant micelle shape transition on the microemulsion viscosity and its application in enhanced oil recovery processes. J Mol Liq. 2014; 198: 286-291.

7. Wang D Q, Yin D Y, Gong X Z. Numerical simulation of microemulsion flooding in lowpermeability reservoir. J Chem-Ny 2019; 2019: 1-8.

8. Zhao G, You Q, Tao J P, Gu C L, Aziz H, Ma L P, et al. Preparation and application of a novel phenolic resin dispersed particle gel for in-depth profile control in low permeability reservoirs. J Petrol Sci Eng 2018; 161: 703-714.

9. Yao C J, Lei G L, Li L, Gao X M. Selectivity of pore-scale elastic microspheres as a novel profile control and oil displacement agent. Energy Fuels 2012; 26(8): 5092-5101.

10. Zhou Z J, Zhao J B, Zhou T, Huang Y M. Study on in-depth profile control system of low-permeability reservoir in block H of Daqing oil field. J Petrol Sci Eng 2017; 157: 1192-1196.

11. Zheng L M, Pu C S, Liu J, Ma B, Khan N. Gel performance in rheology and profile control under low-frequency vibration: Coupling application of physical and chemical EOR techniques. Journal of Petroleum Exploration and Production Technology 2017; 7(2): 479-486.

12. Li L, Han X T, Lin M. Experimental research on profile control for oil displacement by functional polymer in low permeability fractured reservoir. Phys Procedia 2012; 25: 1292-1300. 